Original Research

\title{
Rate of force development and muscle activation of trunk muscles in women with and without low back pain: A case-control study
}

\author{
Denise Martineli Rossi ${ }^{\text {a, * }}$, Mary Hellen Morcelli ${ }^{\text {b }}$, Adalgiso Coscrato Cardozo ${ }^{\text {, }}$ \\ Benedito Sérgio Denadai ${ }^{\text {c }}$, Mauro Gonçalves ${ }^{\text {c }}$, Marcelo Tavella Navega b \\ a Department of Biomechanics, Medicine and Rehabilitation of Locomotor, Ribeirão Preto Medical School, University of São Paulo, Ribeirão Preto, SP, Brazil \\ ${ }^{\mathrm{b}}$ Department of Physical Therapy and Occupational Therapy, São Paulo State University, Marília, SP, Brazil \\ ${ }^{c}$ Department of Physical Education, São Paulo State University, Rio Claro, SP, Brazil
}

\section{A R T I C L E I N F O}

\section{Article history:}

Received 10 March 2016

Received in revised form

22 October 2016

Accepted 26 December 2016

\section{Keywords:}

Muscle strength dynamometer

Abdominal muscles

Electromyography

Low back pain

\begin{abstract}
A B S T R A C T
Objective: To evaluate the rate of force development (RFD) and the rate of electromyography rise (RER) of global and local trunk muscles in women with and without low back pain.

Design: Cross-sectional study.

Setting: Laboratory setting.

Participants: Twenty-eight women divided into low back pain (LBP, $\mathrm{n}=14$ ) and control groups (CG, $\mathrm{n}=14$ ) participated in this study.

Main outcome measures: Subjects performed isometric contractions of trunk using an isokinetic dynamometer, and simultaneously the electromyography (EMG) signals were collected for global (rectus abdominis and longissimus thoracic) and local (internal oblique and multifidus) muscles. All variables were calculated using Matlab software.

Results: Symptomatic subjects showed lower RFD during trunk extension and it was correlated to a reduced RER mainly in the trunk extensor musculature $(\mathrm{p}<0.05)$. During trunk flexion, LBP exhibited a delayed time to reach peak RFD ( $p<0.05$ ) compared to CG. RER for global anterior muscle was higher than for local muscle $(\mathrm{p}<0.05)$ and it was more persistent in asymptomatic women. CG also presented greater activation amplitude for both agonist and antagonist trunk muscles, mainly the global ones. Conclusion: Symptomatic women showed lower RFD and it was correlated to a reduced capacity of rapid muscle activation mainly in the trunk extensor musculature.
\end{abstract}

๑) 2017 Elsevier Ltd. All rights reserved.

\section{Introduction}

Chronic low back pain is one of the most common musculoskeletal symptoms and affects about $60 \%-80 \%$ of the Western population at some point in life (Gaskell, Enright, \& Tyson, 2007). The high rate of disability and its consequent high economic costs to health systems make low back pain a musculoskeletal problem often investigated by the scientific community (Stier-Jarmer, Cieza, Borchers, \& Stucki, 2009). Studies suggest a higher prevalence of musculoskeletal pain, including the low back, in women than in men (Bailey, 2009; Wijnhoven, de Vet, \& Picavet, 2006). Although

\footnotetext{
* Corresponding author. Department of Biomechanics, Medicine and Rehabilitation of Locomotor, Ribeirão Preto Medical School, University of São Paulo, Bandeirantes Avenue, 3900, 14049-900, Ribeirão Preto, SP, Brazil.

E-mail address: denisemartineli@hotmail.com (D.M. Rossi).
}

the reasons remain unclear, the sex differences have been related to psychosocial and physiological factors such as, women are more willing to report pain, more exposure to risk factors and have different pain sensitivity (Bailey, 2009; Wijnhoven et al., 2006). Furthermore, low back pain is a complex phenomenon with numerous causal factors, which need to be better understood. Detailed assessments and investigations of possible causes of low back pain are needed to assist in prescribing intervention programs (Stier-Jarmer et al., 2009).

The literature has shown that subjects with chronic back pain may have reduced strength and endurance of trunk muscles (Gruther et al., 2009; Yahia et al., 2011). Moreover, these subjects can present failures or delays in specific muscle activation (Marshall \& Murphy, 2010; Mehta, Cannella, Smith, \& Silfies, 2010), which can transmit abnormal overload to joint surfaces and cause joint damage and recurrent pain (Lee, Cholewicki, Reeves, Zazulak, \& Mysliwiec, 2010; Newcomer et al., 2002; Oddsson \& De Luca, 


\section{3; Yilmaz et al., 2010).}

In situations with unexpected loads or postural disturbances, a rapid response of trunk control system is required in order to avoid spine injuries (Reeves, Narendra, \& Cholewicki, 2007). The RFD is used to evaluate the ability of subjects to quickly generate force and is usually measured during isometric contractions and single-joint tasks. Although dynamic contractions or multiple-joint movements are more representative of functional tasks, the RFD and its determinants may be influenced by the non-linear mechanisms of dynamic contractions, such as the torque-angle-velocity relationship (Maffiuletti et al., 2016). Moreover, as related to the maximal voluntary contraction, the RFD offers even more sensitivity to detect alterations in neuromuscular function (Peñailillo, Blazevich, Numazawa, \& Nosaka, 2015).

RFD was first studied in athletes, who need rapid muscle responses. RFD, obtained by calculating the slope of the torque-time curve, may be affected by structural muscle and neural factors (Corvino, Caputo, Oliveira, de Greco, \& Denadai, 2009; Aagaard, Simonsen, Andersen, Magnusson, \& Dyhre-Poulsen, 2002). The maximum values of RFD are reached at the beginning of muscle contraction, in a time interval between 100 and 300 milliseconds (Aagaard et al., 2002; Corvino et al., 2009).

RFD has been widely investigated in other populations as a functional parameter in strong and fast contractions, such as in postural balance in the elderly (Lovell, Cuneo, \& Gass, 2010), and in conditions of chronic musculoskeletal pain (Andersen, Holtermann, Jørgensen, \& Sjøgaard, 2008). Andersen et al. (2008) evaluated RFD and RER in patients with trapezius myalgia. This study suggested that the ability to rapidly generate force in synergistic muscles in pain and no-pain conditions is more severely impaired than maximum muscle activation and strength capacity (Andersen et al., 2008). Furthermore, by comparing voluntary contraction and electrical stimulation, literature has shown a strong association between the ability to develop force rapidly and the increase of the agonist muscle activation at the onset of contraction (Blazevich, Cannavan, Horne, Coleman, \& Aagaard, 2009). Additionally, as the recruitment and discharge rate vary depending of the contraction speed, the lower recruitment thresholds evidenced during rapid contractions seems to even inferior for slow-contracting muscles compared to fast contracting muscles (Maffiuletti et al., 2016).

As for the trunk muscles, the literature indicates functional differences, dividing them into local and global. Smaller muscles including the internal oblique (IO) and multifidus (MU) are the principal contributors to the local stabilization system (Bergmark, 1989; Hodges, 2003). Because the local muscles play a stabilizing role acting in the coordination and control of motion segments, they have shown a symmetrical activation even in asymmetric lifting tasks (Borghuis, Hof, \& Lemmink, 2008). The global stabilization system is composed by longer moment arms muscles, such as the rectus abdominis (RA) and longissimus thoracic (LT), that provide more powerful movements and enables the work needed for functional and sport activities (Bergmark, 1989; Hodges, 2003).

Literature supports that strength training can improve the rapid force capacity in different populations (Maffiuletti et al., 2016), including in chronically painful muscles (Andersen et al., 2009). Therefore, investigating the RFD and muscle activation of trunk muscles associated with low back pain symptoms could not only contribute to existing knowledge from a physiological standpoint but also help health professionals to develop rehabilitation strategies based on different types of training for this population. The aims of this study were to evaluate the RFD and the RER for local and global trunk muscles in women with and without chronic low back pain. We hypothesized that subjects with low back pain would have reduced RFD and RER in trunk muscles compared to asymptomatic subjects. Considering the functional role differences, we also hypothesized that greater RER would be produced by global muscles than by local muscles mainly in asymptomatic subjects.

\section{Methods}

\subsection{Subjects}

Subjects for this case-control study were female college students between the ages of 18 and 30 with no history of pregnancy. Twenty-eight female volunteers were divided into two groups, one made up of women with low back pain (LBP, $\mathrm{n}=14$ ) (mean \pm standard deviation; age $24.14 \pm 3.13$ year, mass $61.68 \pm 7.19 \mathrm{~kg}$, height $1.66 \pm 0.05 \mathrm{~m}$, body mass index $22.31 \pm 2.12 \mathrm{~kg} / \mathrm{m}^{2}$ ), and the other a control group (CG) with no history of low back pain (mean \pm standard deviation; age $22.21 \pm 3.40$ year, mass $58.2 \pm 8.73 \mathrm{~kg}$, height $1.61 \pm 0.06$, body mass index $22.23 \pm 1.98 \mathrm{~kg} / \mathrm{m}^{2}$ ). An effect size of 0.99 , a probability error of $\alpha=0.05$, and a power of 0.80 were used to estimate the sample based on peak trunk extensor torque value from a pilot study. Each participant read and signed an informed consent form approved by the local Ethics Research Committee (protocol number 084/2011).

Inclusion criteria for LBP was a reported history of persistent back pain (pain between T12 and the gluteal fold) for longer than 6 months. Exclusion criteria included body mass index higher than $29.9 \mathrm{~kg} / \mathrm{m}^{2}$, history of spinal fracture or surgery, spinal deformity (Larivière, Arsenault, Gravel, Gagnon, \& Loisel, 2003), rheumatologic disorders, neurological symptoms, and vertebral tumors (Gruther et al., 2009).

The assessment protocol was carried out in one day, during which volunteers performed isometric contractions alternating between trunk flexion and extension using an isokinetic dynamometer. Simultaneously, EMG signals were collected bilaterally for anterior and posterior trunk muscles.

\subsection{Isokinetic dynamometer}

Assessment was performed using an isokinetic dynamometer (Biodex ${ }^{\mathbb{B}}$, New York, USA) and special chair (Dual position Back Ex/ Flex Attachment) in the Seated-Compressed mode. Special belts were used to stabilize the participants on the chest, hip, and in the middle third of the thigh. The anterior superior iliac spine was aligned with the dynamometer mechanical axis.

The trunk was maintained at $60^{\circ}$ flexion, and volunteers performed six isometric contractions, three for trunk flexion and three for trunk extension, starting in a random order and alternating (Gruther et al., 2009). Each contraction was maintained for five seconds, with 30 s rest intervals. Subjects were verbally encouraged by the same examiner to expend the greatest and fastest possible effort. The torque signal was corrected for the effect of gravity prior to the assessment. The signal was recorded at $2000 \mathrm{~Hz}$ sample rate, and it was synchronized with EMG signal by a synchronization board (NorBNC, Noraxon ${ }^{\circledR}$, Phoenix, USA).

\subsection{Electromyography}

EMG signals were collected using an 8-channel telemetered electromyogram (TM900, Noraxon ${ }^{\circledR}$, Phoenix, USA) and $\mathrm{Ag} / \mathrm{AgCl}$ surface active electrodes (Miotec ${ }^{\circledR}$, Porto Alegre, Brazil) in bipolar configuration. Before placing the electrodes, the skin was shaved and cleaned with alcohol (Hermens, Freriks, Disselhorst-Klug, \& Rau, 2000).

The electrodes were positioned on both sides of the trunk, right (r) and left (1), for global muscles: rectus abdominis (RA) (Marshall \& Murphy, 2003) and longissimus thoracic (LT) (Hermens et al., 
2000), and local muscles: internal oblique (IO) (Marshall \& Murphy, 2003) and multifidus (MU) (Hermens et al., 2000) (Fig. 1). The reference electrode was located at the radial styloid process.

\subsection{Data analysis}

The RFD and RER were obtained through specific routines developed in Matlab software (Mathworks ${ }^{\mathbb{R}}$, Natick, Massachusetts, USA). A $4^{\text {th }}$ order Butterworth digital filter with a cutoff frequency of $15 \mathrm{~Hz}$ was used to process the torque signal.

RFD was calculated by the slope of the torque-time curve ( $\Delta$ torque/ $\Delta$ time) over time intervals of $0-30 \mathrm{~ms}, 0-50 \mathrm{~ms}$, 0-100 ms, 0-200 ms relative to the onset of contraction (Fig. 2). The onset was determined by the value of $2.5 \%$ from baseline to maximum voluntary contraction (MVC) (Aagaard et al., 2002). In addition, the time needed to reach peak RFD was measured.

The EMG signal was analyzed in the time domain by linear envelope values. The signal was digitally filtered using a $2^{\text {nd }}$ order Butterworth $20 \mathrm{~Hz}$ high-pass filter and a $4^{\text {th }}$ order $500 \mathrm{~Hz}$ low-pass filter. Then, the resulting signal was full-wave rectified and smoothed using a $4^{\text {th }}$ order low-pass Butterworth digital filter with a cutoff frequency of $5 \mathrm{~Hz}$ to create a linear envelope. The EMG onset was determined from two standard deviations from the baseline. Then, RER was calculated from the slope of the rising part of the EMG-time curve at the time intervals of $0-30 \mathrm{~ms}, 0-50 \mathrm{~ms}$, $0-100 \mathrm{~ms}, 0-200 \mathrm{~ms}$ relative to the onset of contraction (Aagaard et al., 2002) (Fig. 2). The RER values were normalized using the root mean square (RMS) peak of the maximal isometric contraction.

The comparisons of the peak torque, RMS, RFD and RER variables between groups were done with a SAS software. A Student $t$ test was used to compare the peak torque and RMS peak. A linear regression mixed model (random intercept and fixed coefficients) was applied on RDF and RER variables which incorporated groups as fixed factor and time intervals (30, 50, 100 and $200 \mathrm{~ms}$ ) as random factors. For the RER variable, the model included orthogonal contrasts to compare different trunk sides (right and left) and muscles (local and global). Log transformation was applied to the non-normally distributed relative to RFD and RER data. Significance level was set at 0.05 . The effect size was calculated by dividing the difference between group mean scores (CG and LBP) by the pooled standard deviation of the 2 groups. The magnitude of the effect size was described as $0.2,0.5$, and 0.8 as small, moderate and large respectively (Cohen, 1988). Bivariate two-tailed Spearman correlation analyses were conducted to determine the relation between RFD and RER at each time interval. The average between right and left side was applied on RER values of each trunk muscle.

\section{Results}

\subsection{Trunk extension}

The CG showed higher peak torque, 203.72 (44.46) Nm, compared to LBP group, 157.35 (48.52) Nm ( $\mathrm{p}=0.014)$. As illustrated in Fig. 3, asymptomatic subjects were able to produce $42.36 \%$ and $34.83 \%$ higher RFD than subjects with low back pain, in time intervals of $0-100 \mathrm{~ms}(\mathrm{p}=0.02), 0-200 \mathrm{~ms}(\mathrm{p}=0.04)$ relative to onset of contraction. No difference was found between groups $(\mathrm{p}=0.077)$ in the time required to reach peak RFD during trunk extension task.

This study found that people with low back pain exhibited a reduced EMG activation of the LT muscle bilaterally, and the OI muscle left side only (Table 1 ). Another finding was an increased antagonist activation of the global muscles in CG during trunk extension (RA muscle bilaterally) and trunk flexion (LT muscle bilaterally and MU muscle left side) (Table 1). The symptomatic group also presented different patterns in the RER for extensor trunk muscles. Both sides of the MU muscle showed lower values in LBP compared to those in asymptomatic subjects at 0-30 ms (left $\mathrm{MU}), 0-50 \mathrm{~ms}$ (left MU), and 0-100 ms (right MU). Symptomatic people also showed decreased RER for the right muscle LT at $0-30 \mathrm{~ms}$ and $0-50 \mathrm{~ms}$. Differences in RER values between right and left sides were found for MU at $0-30 \mathrm{~ms}$ and at peak in the LBP group (Table 2). No differences were observed in the RER between global and local posterior muscles in trunk extension task for either group.

\subsection{Trunk flexion}

There was no evidence of difference between groups for peak torque, with the CG producing 106.36 (20.33) Nm and the LBP group producing $91.92(35.89) \mathrm{Nm}(\mathrm{p}=0.113)$. Subjects with low back pain showed a delayed time $(0.23 \pm 0.16 \mathrm{~s})$ to reach peak RFD compared to asymptomatic subjects $(0.17 \pm 0.07 \mathrm{~s})(\mathrm{p}=0.047$, effect size $=0.49$ ). However, the trunk flexion task did not differ in the RFD between people with and without low back pain (Fig. 3).

As for the activation pattern of the abdominal muscles during the trunk flexion task, this study found differences for the RER values between symptomatic and asymptomatic subjects only for one time interval of the right OI muscle (Table 3).

Supporting our hypotheses, the RER differed between global and

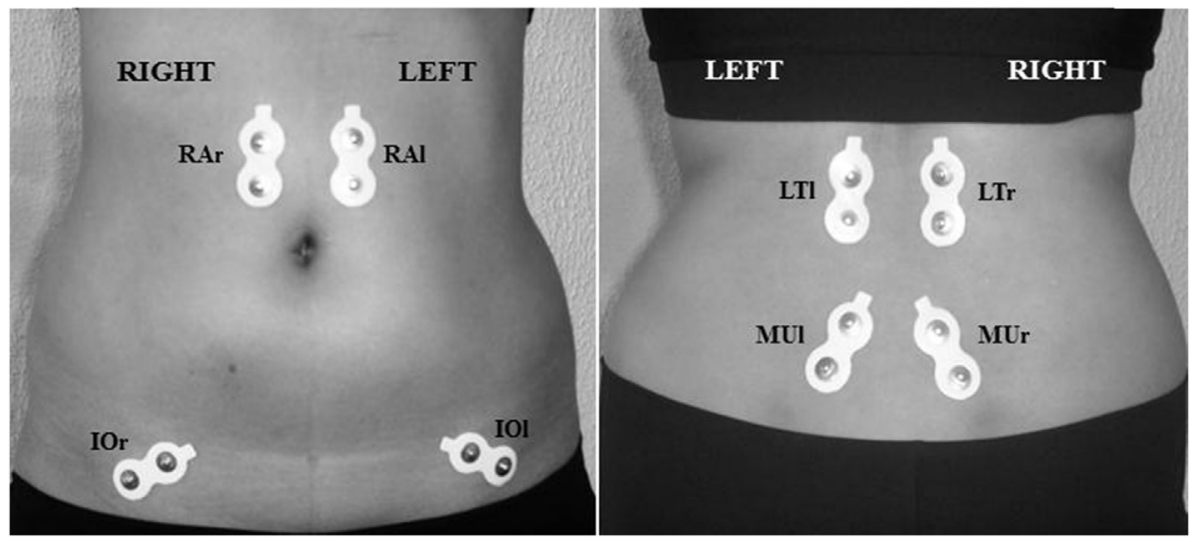

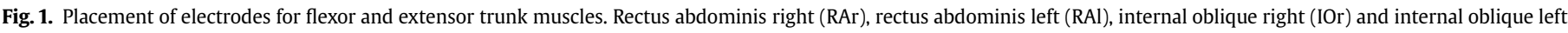
(IOl), longissimus thoracic right (LTr), longissimus thoracic left (LTI), multifidus right (MUr), and multifidus left (MUl). 
$\mathbf{A}$
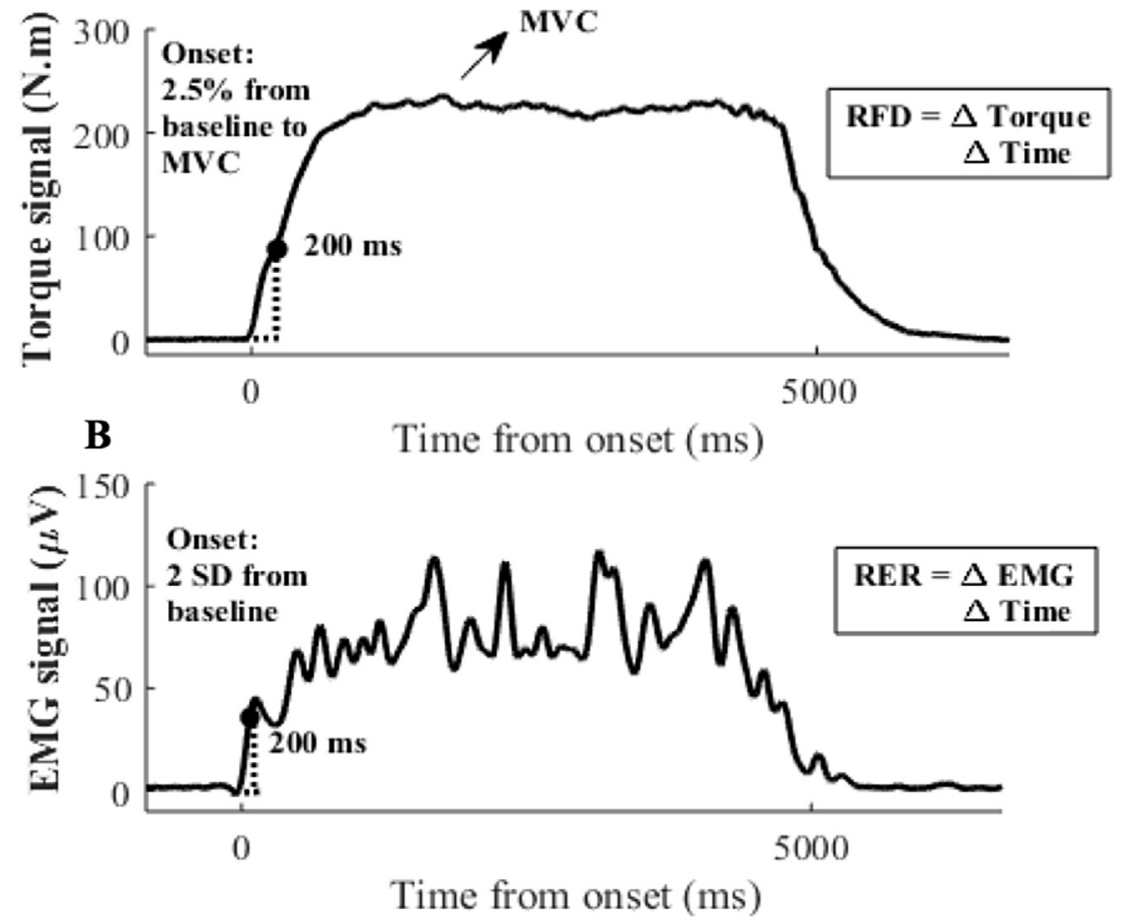

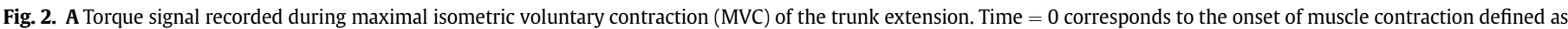

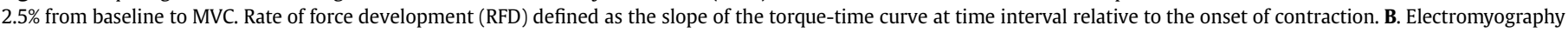

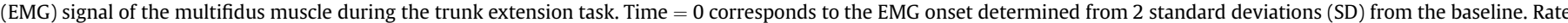

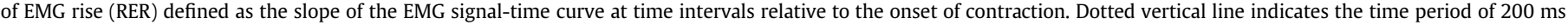
relative to the onset of contraction as an example of how these variables are extracted.
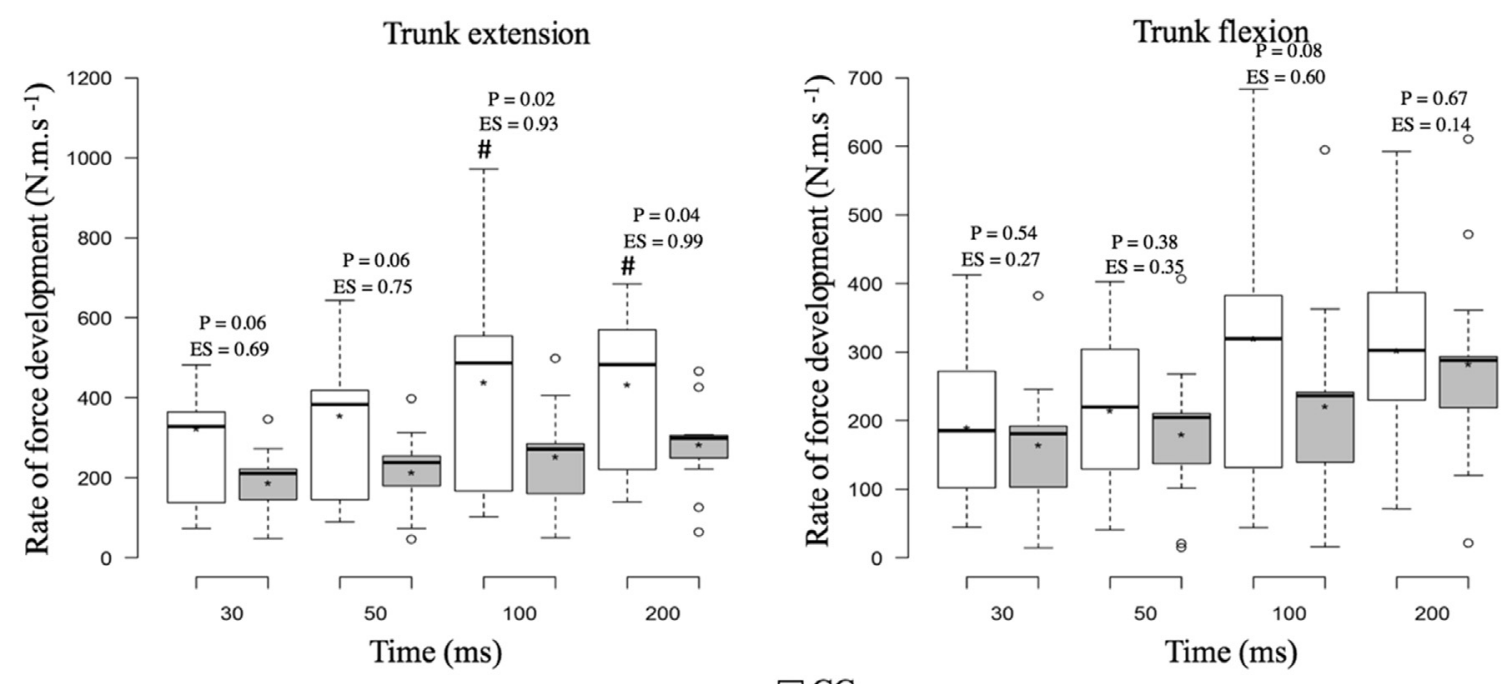

\section{$\square \mathrm{CG}$}

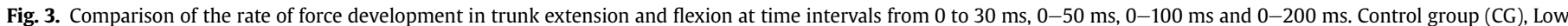
back pain (LBP), Effect size (ES), P value (P). \#p $<0,05$ to CG higher than LBP.

local anterior muscles in both groups. CG and LBP groups showed higher RER of global muscle than of local muscle, but it was more persistent for subjects without low back pain. The global muscle RA left in asymptomatic subjects indicated a higher RER compared to IO left during most time intervals, $0-30 \mathrm{~ms}, 0-50 \mathrm{~ms}, 0-100 \mathrm{~ms}$, and at peak. On the other hand, subjects with low back pain presented differences in the RER in the flexion task between global and local anterior muscles only for the right RA at 0-50 ms.

Significant positive correlation was detected between the RFD and RER for both groups during trunk extension and flexion (Fig. 4). The correlation was more consistent for the CG, mainly during the trunk extension task (Fig. 4). 
Table 1

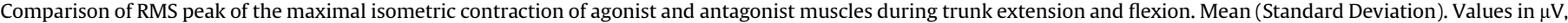
Mean (Standard Deviation), Mean Difference between groups with 95\% Confidence Interval.

\begin{tabular}{|c|c|c|c|c|c|c|}
\hline & & $\mathrm{CG}(\mathrm{n}=14)$ & $\operatorname{LBP}(\mathrm{n}=14)$ & $\begin{array}{l}\text { Mean difference } \\
\mathrm{CI}(95 \%)\end{array}$ & $\begin{array}{l}\text { Effect } \\
\text { Size }\end{array}$ & P value \\
\hline Trunk & $\mathrm{LTr}$ & $108.33(39.10)$ & $68.62(21.27)$ & $39.71(15.25 ; 64.16)$ & 1.26 & $0.003^{*}$ \\
\hline \multirow[t]{7}{*}{ Extension } & LTl & $136.20(84.53)$ & $63.54(28.56)$ & $72.66(23.64 ; 121.68)$ & 1.15 & $0.005^{*}$ \\
\hline & MUr & $70.32(44.04)$ & $50.14(15.14)$ & $20.17(-5.41 ; 45.76)$ & 0.61 & 0.117 \\
\hline & MUl & $68.33(40.28)$ & $57.57(50.60)$ & $10.76(-24.77 ; 46.30)$ & 0.24 & 0.539 \\
\hline & $\mathrm{RAr}$ & $14.61(6.56)$ & $8.68(2.70)$ & $5.93(2.03 ; 9.83)$ & 1.18 & $0.004^{*}$ \\
\hline & RAl & $18.83(11.53)$ & $8.07(3.44)$ & $10.76(4.14 ; 17.36)$ & 1.32 & $0.002^{*}$ \\
\hline & OIr & $35.74(27.17)$ & $19.64(11.06)$ & $16.10(-0.02 ; 32.21)$ & 0.78 & 0.050 \\
\hline & OIl & $36.55(28.41)$ & $29.21(17.84)$ & $7.34(-11.09 ; 25.77)$ & 0.31 & 0.420 \\
\hline Trunk & $\mathrm{RAr}$ & $101.22(89.65)$ & 74.59 (95.57) & $26.63(-45.38 ; 98.63)$ & 0.29 & 0.454 \\
\hline \multirow[t]{7}{*}{ Flexion } & RAl & $92.83(86.41)$ & $48.01(36.38)$ & $44.81(-6.69 ; 96.32)$ & 0.68 & 0.085 \\
\hline & OIr & $155.92(82.79)$ & $125.45(47.47)$ & $30.47(-62.44 ; 123.38)$ & 0.45 & 0.506 \\
\hline & OIl & $211.88(132.92)$ & $92.22(51.25)$ & $119.66(26.88 ; 212.44)$ & 1.19 & $0.013^{*}$ \\
\hline & $\mathrm{LTr}$ & $27.57(13.4)$ & $14.58(8.53)$ & $12.99(4.26 ; 21.10)$ & 1.16 & $0.005^{*}$ \\
\hline & LTl & $27.13(16)$ & $14.92(6.88)$ & $12.21(2.64 ; 21.78)$ & 0.99 & $0.014^{*}$ \\
\hline & MUr & $23.43(14.4)$ & $19.29(14.3)$ & $4.14(-7.00 ; 15.29)$ & 0.29 & 0.451 \\
\hline & MUl & $26.26(10.8)$ & $12.74(5.09)$ & $13.52(6.97 ; 20.08)$ & 1.60 & $0.001^{*}$ \\
\hline
\end{tabular}

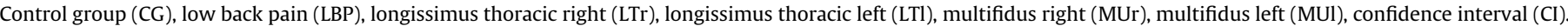
${ }^{*} \mathrm{p}<0.05$ to CG higher than LBP.

Table 2

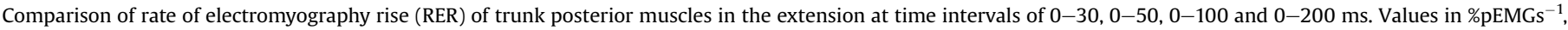
Mean (Standard Deviation), Mean Difference between groups with 95\% Confidence Interval.

\begin{tabular}{|c|c|c|c|c|c|c|}
\hline & Time & $C G(n=14)$ & $\operatorname{LBP}(n=14)$ & $\begin{array}{l}\text { Mean Difference } \\
\text { CI (95\%) }\end{array}$ & $\begin{array}{l}\text { Effect } \\
\text { Size }\end{array}$ & P value \\
\hline \multirow[t]{4}{*}{ LTr } & 30 & $355.10(164.04)$ & 217.99 (142.79) & $137.11(18.83 ; 255.39)$ & 0.89 & $0.023^{*}$ \\
\hline & 50 & 372.78 (177.77) & $245.60(154.39)$ & $127.18(8.90 ; 245.46)$ & 0.71 & $0.035^{*}$ \\
\hline & 100 & $330.60(171.93)$ & $271.34(171.67)$ & $59.27(-59.01 ; 177.54)$ & 0.34 & 0.325 \\
\hline & 200 & $184.15(86.10)$ & 198.35 (135.39) & $-14.20(-132.48 ; 104.07)$ & -0.13 & 0.814 \\
\hline \multirow[t]{4}{*}{ LTl } & 30 & $272.38(131.28)$ & $222.87(105.53)$ & $49.51(-68.77 ; 167.79)$ & 0.42 & 0.411 \\
\hline & 50 & $293.48(150.86)$ & $248.31(112.45)$ & $45.16(-73.11 ; 163.44)$ & 0.34 & 0.453 \\
\hline & 100 & $280.31(158.49)$ & $267.05(118.11)$ & $13.26(-105.02 ; 131.54)$ & 0.09 & 0.826 \\
\hline & 200 & $155.04(68.94)$ & 219.14 (110.99) & $-64.10(-182.38 ; 54.18)$ & 0.0 .70 & 0.288 \\
\hline \multirow[t]{4}{*}{ MUr } & 30 & $362.19(223.65)$ & $271.76(182.51) €$ & $90.42(0.13 ;-27.85)$ & 0.44 & 0.134 \\
\hline & 50 & $389.14(231.12)$ & $286.54(180.53)$ & $102.60(-15.68 ; 220.88)$ & 0.49 & 0.089 \\
\hline & 100 & $379.58(217.72)$ & $261.09(154.22)$ & $118.49(0.21 ; 236.77)$ & 0.63 & $0.049 *$ \\
\hline & 200 & $251.95(160.69)$ & $206.22(92.59)$ & $45.74(-72.54 ; 164.02)$ & 0.35 & 0.448 \\
\hline \multirow[t]{4}{*}{ MUl } & 30 & $319.63(162.25)$ & $172.07(130.07)$ & $147.57(29.29 ; 265.85)$ & 1.00 & $0.015^{*}$ \\
\hline & 50 & $340.45(182.74)$ & $199.48(144.30)$ & $140.96(22.69 ; 259.24)$ & 0.86 & $0.019^{*}$ \\
\hline & 100 & $327.45(196.54)$ & $232.05(146.38)$ & $95.39(-22.88 ; 213.68)$ & 0.55 & 0.114 \\
\hline & 200 & $222.79(113.01)$ & $205.62(117.39)$ & $17.17(-101.10 ; 135.45)$ & 0.15 & 0.776 \\
\hline
\end{tabular}

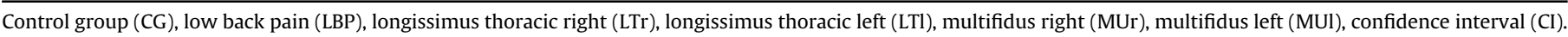
*p $<0.05$ to CG higher than LBP.

$€ \mathrm{p}<0.05$ to right higher than left side.

\section{Discussion}

Our findings indicate that asymptomatic subjects have greater ability to generate force quickly during trunk extension compared to subjects with chronic low back pain. The RFD is suitable to determine neuromuscular function and strongly governed by diverse physiological mechanisms such as the capacity of rapid muscle activation in the early phase of an explosive contraction (Maffiuletti et al., 2016; Peñailillo et al., 2015). In agreement with the evidence that the MVC force is also a potential determinant mainly in a late-phase RFD (Maffiuletti et al., 2016), this study found a reduced peak torque during trunk extension task in the LBP group. A strength deficit of these muscles is also demonstrated in the literature in subjects with chronic low back pain compared to asymptomatic subjects (Gruther et al., 2009; Yahia et al., 2011).

Evidence of difference between groups was found in a latephase RFD, i.e., on time intervals at $100 \mathrm{~ms}$ and $200 \mathrm{~ms}$, suggesting contractile factors as critical determinants to muscle strength (Maffiuletti et al., 2016). At the beginning of muscle contraction $(<75 \mathrm{~ms})$ of a rapid contraction, the RFD is influenced by intrinsic muscle properties, which relate to the intensity of efferent motor neuron production, or to the frequency of activation and the recruitment of motor neurons. A greater inter-subject variability has been suggested during the early phase of the contraction which the neural factors are predominant (Folland, Buckthorpe, \& Hannah, 2014). For later time intervals (>75 ms), changes in RFD have a strong relationship to aspects related to the production of maximum muscular strength, muscle size, relative area of fast twitch fibers, and muscle fiber distribution (Andersen \& Aagaard, 2006; Blazevich, Horne, Cannavan, Coleman, \& Aagaard, 2008; Folland et al., 2014).

Despite the lack of evidence of difference between groups in RFD values in trunk flexion, this study suggests temporal differences, in which asymptomatic subjects reached peak RFD in a shorter time than subjects with low back pain. The literature has shown that subjects with this symptom present changes in motor control such as delayed onset of trunk muscle activation during rapid movements of the upper limbs that cause disturbances in the body's balance (Marshall \& Murphy, 2010; Mehta et al., 2010).

Regarding muscle activation, this study found that during the 
Table 3

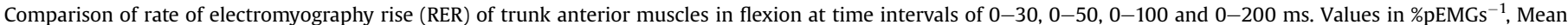
(Standard Deviation), Mean Difference between groups with 95\% Confidence Interval.

\begin{tabular}{|c|c|c|c|c|c|c|}
\hline & Time & $\mathrm{CG}(\mathrm{n}=14)$ & $\operatorname{LBP}(n=14)$ & $\begin{array}{l}\text { Mean difference } \\
\mathrm{CI}(95 \%)\end{array}$ & $\begin{array}{l}\text { Effect } \\
\text { Size }\end{array}$ & $P$ value \\
\hline \multirow[t]{4}{*}{ RAr } & 30 & 391.25 (197.95) & $274.76(218.21)$ & $116.50(-19.57 ; 252.58)$ & 0.66 & 0.093 \\
\hline & 50 & $407.86(221.66)$ & 306.50 (235.32) \# & $101.36(-34.72 ; 237.44)$ & 0.60 & 0.144 \\
\hline & 100 & $371.27(203.01)$ & $312.09(207.98)$ & $59.18(-76.89 ; 195.26)$ & 0.35 & 0.393 \\
\hline & 200 & $188.98(88.50)$ & $167.39(74.92)$ & $21.59(-114.49 ; 157.66)$ & 0.18 & 0.755 \\
\hline \multirow[t]{4}{*}{ RAl } & 30 & 361.43 (280.14) \# & $286.72(124.21)$ & $74.71(-61.37 ; 210.79)$ & 0.33 & 0.281 \\
\hline & 50 & 393.67 (305.83) \# & $318.49(128.94)$ & $75.18(-60.90 ; 211.25)$ & 0.32 & 0.278 \\
\hline & 100 & 371.64 (267.50) \# & $317.45(125.00)$ & $54.19(-81.88 ; 190.28)$ & 0.26 & 0.434 \\
\hline & 200 & $172.93(95.93)$ & $176.18(58.04)$ & $-3.25(-139.32 ; 132.83)$ & -0.04 & 0.962 \\
\hline \multirow[t]{4}{*}{ IOr } & 30 & $307.22(197.40)$ & $178.89(135.22)$ & $128.33(-7.75 ; 264.40)$ & 0.76 & 0.065 \\
\hline & 50 & $341.80(215.55)$ & $204.91(151.31)$ & $136.89(0.80 ; 272.96)$ & 0.74 & $0.048^{*}$ \\
\hline & 100 & $350.48(208.58)$ & $230.19(177.06)$ & $120.29(-15.78 ; 256.37)$ & 0.62 & 0.083 \\
\hline & 200 & $208.74(114.80)$ & $149.38(109.70)$ & $59.36(-76.72 ; 195.43)$ & 0.53 & 0.392 \\
\hline \multirow[t]{4}{*}{$\mathrm{IOl}$} & 30 & $246.55(164.51)$ & $209.70(121.81)$ & $36.84(-99.23 ; 172.92)$ & 0.25 & 0.595 \\
\hline & 50 & $267.50(179.64)$ & $235.73(142.95)$ & $31.77(-104.31 ; 167.85)$ & 0.20 & 0.646 \\
\hline & 100 & $255.95(177.10)$ & 251.05 (166.99) & $4.90(-131.18 ; 140.98)$ & 0.03 & 0.944 \\
\hline & 200 & $130.91(86.48)$ & $157.45(88.92)$ & $-26.53(-162.61 ; 109.54)$ & -0.30 & 0.701 \\
\hline
\end{tabular}

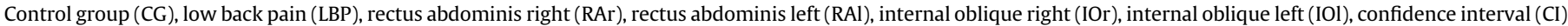
* $\mathrm{p}<0.05$ to CG higher than LBP.

\# $\mathrm{p}<0.05$ to global higher than local.

Trunk extension

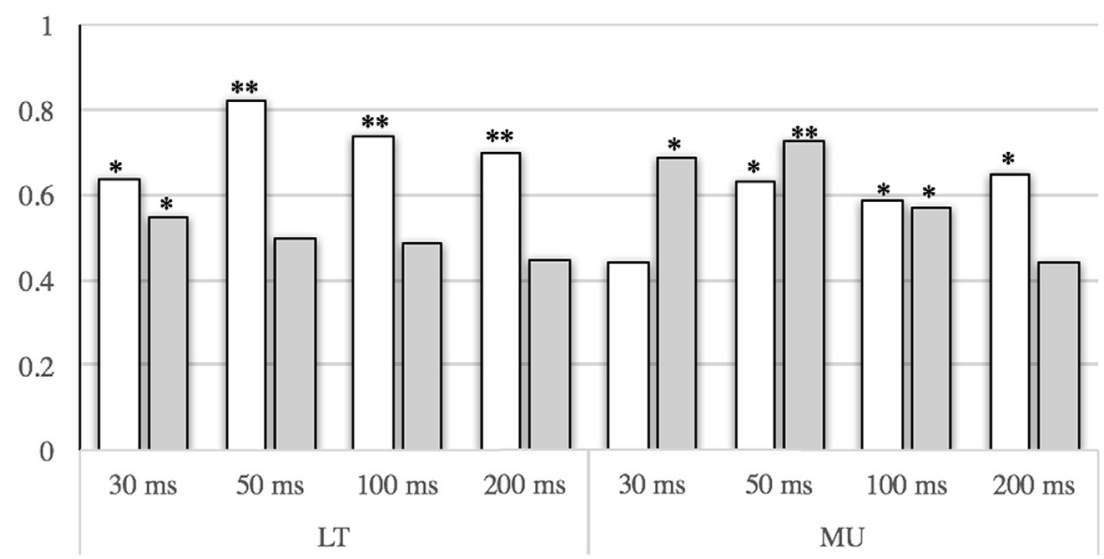

Trunk flexion

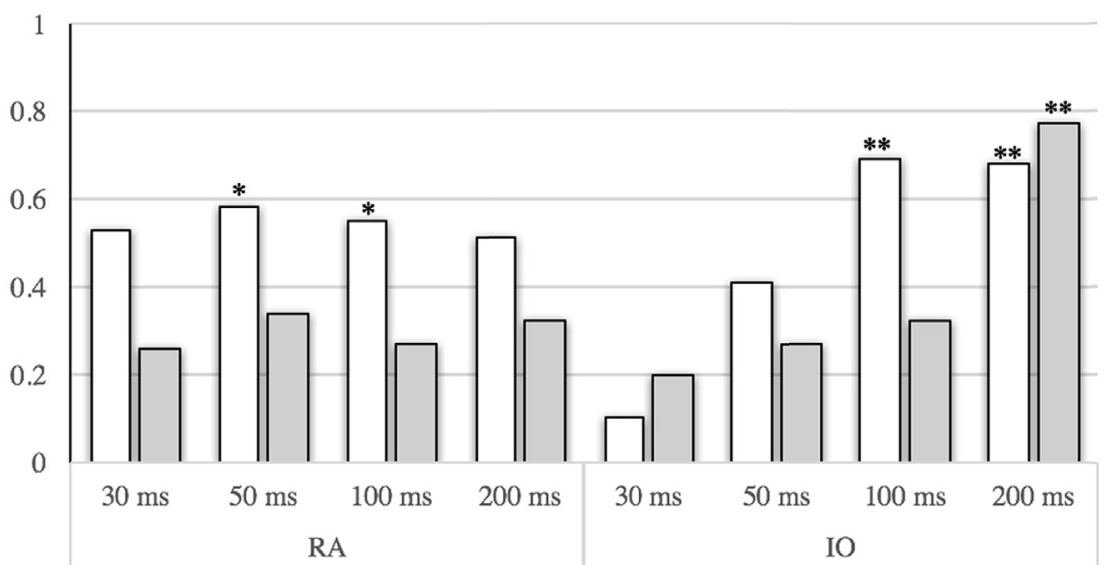

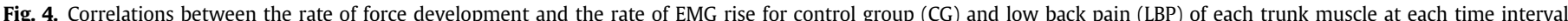
(30 ms, $50 \mathrm{~ms}, 100 \mathrm{~ms}$ and $200 \mathrm{~ms}$ ). Longissimus thoracic (LT), multifidus (MU), rectus abdominis (RA) and internal oblique (IO).

Correlation is significatn at the 0.01 level.

${ }^{*}$ Correlation is significant at the 0.05 level. 
trunk extension, the CG produced higher amplitude activation of the global agonist muscles (LT bilaterally) and also higher antagonist muscle activation (RA bilaterally) compared to LBP. During trunk flexion, the CG presented higher antagonist muscle activation of LT muscle bilaterally and MU left side compared to the LBP group. In agreement with our results, Hirata, Salomoni, Christensen, and Graven-Nielsen (2015) have also evidenced an increased antagonist activation of abdominal muscles (RA and external oblique) while increasing the force level during isometric trunk extension as a suggested strategy to improve stability in pain free situations (Hirata et al., 2015). Furthermore, during a pain experimental condition, decreased antagonist muscle activity during trunk extension has been reported, which may impair trunk stiffness (Hirata et al., 2015). A strong association has also been reported between proportional changes in RER and RFD after a resistance training program in both agonist and antagonist knee muscles. This increased rate of antagonist activation after training has been suggested as a protective mechanism in response to the increased agonist RER (Blazevich et al., 2008).

The RER of trunk extensor global muscle and local muscle activity was also higher in asymptomatic subjects than in women with low back pain in this study. Additionally, a strong association between RER and RFD, mainly for CG during trunk extension, was found, suggesting that the increased motoneuron excitability and the decreased presynaptic inhibition might increase the capacity to generate force quickly (Aagaard et al., 2002; Blazevich et al., 2008).

A reduced capacity to generate rapid force during a MVC has already been demonstrated in painful conditions. Specifically, women with trapezius myalgia have been reported to present with reduced RFD and RER compared to healthy controls (Andersen et al., 2008). Additionally, these variables have been suggested as a useful clinical tool by being very sensitive in response to rehabilitation (Andersen et al., 2009). Andersen et al. (2009) demonstrated a significant improvement in the rapid force capacity after a specific strength protocol suggesting general effects of strength training, pain reduction and mainly neural adaptations as predominant mechanisms.

Although there is a belief that rapid movements exacerbate pain, a multivariate linear regression analyses showed nonsignificant relationships between pain and pain related fear and functional capacity evaluation in patients with low back pain symptoms (Reneman, Preuper, Kleen, Geertzen, Dijkstra, 2007). Moreover, the neural inhibitory feedback due the pain has a minimal effect on RFD and RER because these variables are measured in a very brief time interval from the onset of contraction to the steepest portion of the torque-time curve (Andersen et al., 2008). Good reliability of MVC for amplitude normalization was suggested for assessing EMG signal of trunk muscles within-days, but subMVC showed greater reliability of measurements between different-days. Dankaerts, O'Sullivan, Burnett, Straker, and Danneels (2004) showed good reliability of MVC for amplitude normalization for assessing EMG signal of trunk muscles withindays and greater reliability for sub-MVC between different-days. Additionally, a similar reliability was seen in the healthy control and the low back pain groups supporting the evidence of no influence of pain as the source of measurement error (Dankaerts et al., 2004).

For intra-group comparisons during the trunk flexion task, the CG showed the greatest differences between global muscles and local muscles; in these instances, RA left was higher than IO left for several time intervals. The larger lever arm of global muscles produces a greater level of torque output and greater control of the external forces than do the local muscles (Bergmark, 1989; Hodges, 2003). Thus, a greater RER for global compared to local muscles in asymptomatic women might account for a shorter time to reach
RFD peak. However, differences in RER between groups was not sufficient to interfere with the RFD during the trunk flexion task. The present study did not find relevant differences between left and right sides of trunk muscle activity. Oddsson and De Luca (2003) suggested that both asymptomatic and symptomatic subjects presented uncompensated RMS imbalances defined as a global uneven activation even during a symmetrical isometric task (Oddsson \& De Luca, 2003).

The reduced RFD and RER mainly during trunk extension in subjects with low back pain might be useful in a clinical setting. For example, the initial phase of an intervention program could focus on high level of muscle activation exercises, and the later phases could include more powerful exercises mainly for the extensor musculature.

Our study has some limitations. The level of disability and pain was not estimated for the LBP group. Considering the heterogeneity of the population with low back pain, this information could be useful to determine the severity of clinical conditions. Furthermore, in this sense, the division of symptomatic group into subgroups could be interesting. Finally, our sample consisted of young women, but low back pain seems to affect older subjects more severely.

\section{Conclusion}

This study demonstrates that women with chronic low back pain have a deficit in their ability to generate force quickly. Additionally, this deficit was correlated to a reduced capacity of rapid muscle activation, mainly in the trunk extensor musculature. Accordingly, asymptomatic women exhibited a different muscle pattern presenting higher activation for both agonist and antagonist trunk muscles, mainly in the global musculature.

\section{Ethical approval}

This study was approved by the Ethics Research Committee of São Paulo State University under the protocol n 084/2011.

\section{Funding}

None declared.

\section{Conflict of interest}

None declared.

\section{Acknowledgements}

Denise Martineli Rossi would like to acknowledge CAPES for the scholarship. The authors would like to thank all participants in this study.

\section{References}

Aagaard, P., Simonsen, E. B., Andersen, J. L., Magnusson, P., \& Dyhre-Poulsen, P. (2002). Increased rate of force development and neural drive of human skeletal muscle following resistance training. J Appl Physiol, 93(4), 1318-1326.

Andersen, L. L., \& Aagaard, P. (2006). Influence of maximal muscle strength and intrinsic muscle contractile properties on contractile rate of force development. Eur J Appl Physiol, 96(1), 46-52.

Andersen, L. L., Andersen, J. L., Suetta, C., Kjaer, M., Sogaard, K., \& Sjogaard, G. (2009). Effect of contrasting physical exercise interventions on rapid force capacity of chronically painful muscles. Journal of Applied Physiology, 107(5), 1413-1419.

Andersen, L. L., Holtermann, A., Jørgensen, M. B., \& Sjøgaard, G. (2008). Rapid muscle activation and force capacity in conditions of chronic musculoskeletal pain. Clinical Biomechanics Bristol Avon, 23(10), 1237-1242.

Bailey, A. (2009). Risk factors for low back pain in women: Still more questions to be answered. Menopause, 16(1), 3-4. 
Bergmark, A. (1989). Stability of the lumbar spine. A study in mechanical engineering. Acta orthopaedica Scandinavica Supplementum, 230, 1-54.

Blazevich, A. J., Cannavan, D., Horne, S., Coleman, D. R., \& Aagaard, P. (2009). Changes in muscle force-length properties affect the early rise of force in vivo. Muscle Nerve, 39, 512-520.

Blazevich, A. J., Horne, S., Cannavan, D., Coleman, D. R., \& Aagaard, P. (2008). Effect of contraction mode of slow-speed resistance training on the maximum rate of force development in the human quadriceps. Muscle Nerve., 38(3), 1133-1146.

Borghuis, J., Hof, A. L., \& Lemmink, A. P. M. (2008). The importance of sensory-motor control in providing core stability. Implication for measurement and training. Sports Medicine, 38(11), 893-916.

Cohen, J. (1988). Statistical power analysis for the behavioral sciences (2nd ed.). New Jersey: Academic Press.

Corvino, R. B., Caputo, F., Oliveira, A. C., de, Greco, C. C., \& Denadai, B. S. (2009). Taxa de desenvolvimento de força em diferentes velocidades de contrações musculares. Revista Brasileira de Medicina do Esporte, 15(6).

Dankaerts, W., O'Sullivan, P. B., Burnett, A. F., Straker, L. M., \& Danneels, L. A. (2004) Reliability of EMG measurements for trunk muscles during maximal and submaximal voluntary isometric contractions in healthy controls and CLBP patients. J Electromyogr Kinesiol., 14, 333-342.

Folland, J. P., Buckthorpe, M. W., \& Hannah, R. (2014). Human capacity for explosive force production: Neural and contractile determinants. Scand J Med Sci Sports, 24, 894-906.

Gaskell, L., Enright, S., \& Tyson, S. (2007). The effects of a back rehabilitation programme for patients with chronic low back pain. Journal of Evaluation in Clinical Practice, 13(5), 795-800.

Gruther, W., Wick, F., Paul, B., Leitner, C., Posch, M., Matzner, M., et al. (2009). Diagnostic accuracy and reliability of muscle strength and endurance measurements in patients with chronic low back pain. Journal of Rehabilitation Medicine, 41(8), 613-619.

Hermens, H. J., Freriks, B., Disselhorst-Klug, C., \& Rau, G. (2000). Development of recommendations for SEMG sensors and sensor placement procedures. J Electromyogr Kinesiol., 10(5), 361-374.

Hirata, R. P., Salomoni, S. E., Christensen, S. W., \& Graven-Nielsen, T. (2015). Reorganised motor control strategies of trunk muscle due to acute low back pain. Human Movement Science, 41, 282-294.

Hodges, P. W. (2003). Core stability exercise in chronic low back pain. Orthopedic Clinics of North America, 34(2), 245-254.

Larivière, C., Arsenault, A. B., Gravel, D., Gagnon, D., \& Loisel, P. (2003). Surface electromyography assessment of back muscle intrinsic properties. I Electromyogr Kinesiol., 13(4), 305-318.

Lee, A. S., Cholewicki, J., Reeves, N. P., Zazulak, B. T., \& Mysliwiec, L. W. (2010), Comparison of trunk proprioception between patients with low back pain and healthy controls. Archives of Physical Medicine and Rehabilitation, 91(9), 1327-1331.
Lovell, D. I., Cuneo, R., \& Gass, G. C. (2010). The effect of strength training and shortterm detraining on maximum force and the rate of force development of older men. European Journal of Applied Physiology, 109(3), 429-435.

Maffiuletti, N. A., Aagaard, P., Blazevich, A. J., Folland, J., Tillin, N., \& Duchateau, J. (2016). Rate of force development: Physiological and methodological considerations. European Journal of Applied Physiology, 116, 1091-1116.

Marshall, P., \& Murphy, B. (2003). The validity and reliability of surface EMG to assess the neuromuscular response of the abdominal muscles to rapid limb movement. Journal of Electromyography and Kinesiology, 13(5), 477-489.

Marshall, P., \& Murphy, B. (2010). Delayed abdominal muscle onsets and self-report measures of pain and disability in chronic low back pain. Journal of Electromyography \& Kinesiology, 20(5), 833-839.

Mehta, R., Cannella, M., Smith, S. S., \& Silfies, S. P. (2010). Altered trunk motor planning in patients with nonspecific low back pain. Journal of Motor Behavior, 42(2), 135-144.

Newcomer, K. L., Jacobson, T. D., Gabriel, D. A., Larson, D. R., Brey, R. H., \& An, K. N. (2002). Muscle activation patterns in subjects with and without low back pain. Archives of Physical Medicine and Rehabilitation, 83(6), 816-821.

Oddsson, L. I. E., \& De Luca, C. J. (2003). Activation imbalances in lumbar spine muscles in the presence of chronic low back pain. Journal of Applied Physiology, 94(4), 1410-1420.

Peñailillo, L., Blazevich, A., Numazawa, H., \& Nosaka, K. (2015). Rate of force development as a measure of muscle damage. Scand J Med Sci Sports, 25, 417-427.

Reeves, N. P., Narendra, K. S., \& Cholewicki, J. (2007). Spine stability: The six blind men and the elephant. Clinical Biomechanics, 22(3), 266-274.

Reneman, M. F., Schiphorts Preuper, H. R., Kleen, M., Geertzen, J. H., \& Dijkstra, P. U. (2007). Are pain intensity and pain related fear related to functional capacity evaluation performances of patients with chronic low back pain? Journal of Occupational Rehabilitation, 17, 247-258.

Stier-Jarmer, M., Cieza, A., Borchers, M., \& Stucki, G. (2009). World Health Organization. How to apply the ICF and ICF core sets for low back pain. Clin J Pain. 25(1), 29-38.

Wijnhoven, H. A. H., de Vet, H. C. W. \& Picavet, H. S. J. (2006). Explaining sex differences in chronic musculoskeletal pain in a general population. Pain, 124(1-2), 158-166.

Yahia, A., Jribi, S., Ghroubi, S., Elleuch, M., Baklouti, S., \& Habib Elleuch, M. (2011). Evaluation of the posture and muscular strength of the trunk and inferior members of patients with chronic lumbar pain. Joint Bone Spine, 78(3), 291-297.

Yilmaz, B. Yasar, E. Taskaynatan, M. A. Goktepe, A. S., Tugcu, I. Yazicioglu, K., et al. (2010). Relationship between lumbar muscle strength and proprioception after fatigue in men with chronic low back pain. Turkish Journal of Rheumatology 25(2), 68-71. 